\title{
Diurnal variations in plasma testosterone in a male nocturnal primate, the owl monkey (Aotus trivirgatus)
}

\author{
A. F. Dixson and J. S. Gardner \\ Institute of Zoology, Wellcome Laboratories of Comparative Physiology, Zoological Society of \\ London, Regent's Park, London NWI 4RY, U.K.
}

\begin{abstract}
Summary. Six adult male owl monkeys were kept in conditions of controlled lighting ( $12 \mathrm{~h}$ white light alternating with $12 \mathrm{~h}$ of very dim red light) and blood samples were taken at different times of day, once a week, for 10 weeks. Plasma testosterone levels correlated with phases of the lighting cycle: highest levels (mean \pm s.e.m.) occurred in the light $(24.8 \pm 5.3 \mathrm{ng} / \mathrm{ml})$ and lowest levels during periods of darkness $(4.7 \pm$ $1.2 \mathrm{ng} / \mathrm{ml})$. The owl monkey is nocturnal, and these daily changes in circulating testosterone are the reverse of those reported for some diurnal primates, although the timing of the high and low levels in relation to activity patterns is similar.
\end{abstract}

\section{Introduction}

Daily variations in concentrations of circulating testosterone are known to occur in males of several primate species. In animals with diurnal patterns of activity, testosterone levels are elevated during the night when the animals are least active or asleep (rhesus monkey: Goodman, Hotchkiss, Karsch \& Knobil, 1974; Michael, Setchell \& Plant, 1974; bonnet monkeys: Mukku, Prahalda \& Moudgal, 1976; ring-tailed lemur: Van Horn, Beamer \& Dixson, 1976). In human males, however, a peak of testosterone of about $7 \mathrm{ng} / \mathrm{ml}$ between 07:00 and 08:00 h has been reported and the lowest levels, of about $5 \mathrm{ng} / \mathrm{ml}$, occur between 22:00 and 24:00 h (Lincoln, Rowe \& Racey, 1974). It is not known to what extent these fluctuations are influenced by changes in prevailing light intensity, activity patterns or other factors. Mukku et al. (1976) found that exposure to constant light for 4 weeks abolished the nocturnal rise of testosterone in bonnet monkeys and led to a reduction in circulating testosterone. They pointed out that the alteration in testosterone levels could have resulted, in part, from the effects of stress. Mukku et al. (1976) did not measure activity.

Additional information could be obtained by comparative studies of nocturnal primates, in which activity cycles are, broadly speaking, the reverse of those exhibited by diurnal animals. We report here on daily variations in plasma testosterone in the owl monkey (Aotus trivirgatus) which is the only nocturnal anthropoid primate (Moynihan, 1964; Kavanau \& Peters, 1976).

\section{Materials and Methods}

\section{Animals, caging and lighting}

Six male Colombian owl monkeys (Aotus trivirgatus griseimembra) were used. The animals were adult, as judged by body weight $(800-1000 \mathrm{~g})$, testicular volume and size of the subcaudal gland, which develops at puberty in males of this species (Dixson, Gardner \& Bonney, 1980). They had been in captivity for more than 3 years. The animals were kept in cages measuring 102 
$\times 111 \times 66 \mathrm{~cm}$, some of which were provided with a central dividing screen. A nest box, which provided means of trapping the monkey was attached to each cage. Artificial lighting was controlled by time switches and consisted of $12 \mathrm{~h}$ white light (01:00-13:00 h) alternating with 12 $\mathrm{h}$ very dim red light. Details of the management and diet are provided elsewhere (Dixson et al., 1980).

\section{Collection of blood samples}

To avoid potentially stressful effects of repeated blood sampling during the same $24 \mathrm{~h}$ period, samples were taken at weekly intervals, at different times of the day, for 10 consecutive weeks. The times and order of sample collections were as follows: 11:00, 11:00, 11:00, 15:00, 19:00, 23:00, 03:00, 07:00, 11:00 and 11:00 h for Weeks $1,2,3,4,5,6,7,8,9$ and 10 respectively. Samples taken at $11: 00 \mathrm{~h}$ at the beginning and end of the experiment provided a baseline against which to compare the intervening sampling times. Monkeys were restrained by means of a movable metal plate inside the nest boxes and tranquillized by an intramuscular injection of 20 $\mathrm{mg}$ ketamine hydrochloride (Vetalar; Parke Davis). Blood (1.0-1.5 ml) was collected from the femoral vessels into a heparinized syringe. After centrifugation the plasma was stored at $-20^{\circ} \mathrm{C}$ until assayed for testosterone. If an animal failed to enter its nest box readily on any given day, then no sample was collected.

\section{Testosterone assay}

Plasma testosterone was measured by radioimmunoassay as previously described (Dixson $e t$ al., 1980). All the plasma samples were processed at the same time. The goat anti-testosterone serum employed (Gamma G, Beaconsfield, U.K.) exhibits a 100\% cross-reaction with testosterone and $45 \%$ with dihydrotestosterone (DHT). Cross-reactivities with androstenedione, dehydroepiandrosterone, cortisol, progesterone, oestradiol, oestrone and oestriol were all $<0 \cdot 1 \%$. The maximum sensitivity of the assay, defined as the precision of measurement of a zero quantity, was $0 \cdot 18 \mathrm{ng} / \mathrm{ml}$. Since the cross-reactivity with DHT was $45 \%$, testosterone and DHT levels were measured after chromatographic separation in 27 plasma samples from adult male owl monkeys. DHT was non-detectable $(<0.2 \mathrm{ng} / \mathrm{ml})$ in all samples and testosterone levels before and after chromatography did not differ significantly (Student's $t$ test, $P>0.2$ ). It was therefore considered unlikely that cross-reactivity with DHT interfered significantly with measurements of testosterone.

\section{Results}

Analysis of variance revealed a significant difference in testosterone levels measured at weekly intervals $(\mathrm{F}=3 \cdot 06$, d.f. $=9,40, P<0 \cdot 01)$. These marked differences in plasma testosterone concentrations correlated with the phases of the lighting cycle (Text-fig. 1). In Weeks 1, 2 and 3 mean testosterone levels were high $(18.4,22.3$ and $24.8 \mathrm{ng} / \mathrm{ml}$ respectively) in samples collected in the light at 11:00 h. Testosterone averaged only $4.7 \mathrm{ng} / \mathrm{ml}$ in samples taken at 15:00 h (Week 4) during the dark phase and were also low at 19:00 and 23:00 h in Weeks 5 and 6 respectively. A return to high levels of testosterone was observed during Weeks 7-10 when samples were again collected in the light. Testosterone concentrations at 11:00 h in Week 10 averaged 23.1 $\mathrm{ng} / \mathrm{ml}$ and did not differ significantly from those recorded at the same sampling time in Week 1 $(t=0.4035$, d.f. $=4)$.

One male failed to enter his nest box readily and blood samples were only obtained in Weeks $1-3$. In the remaining 5 males testosterone concentrations were consistently lower in samples taken during the hours of darkness than in the light. Nocturnal levels (Weeks 4-6) were 
significantly lower than those in the light in Weeks $1-3(t=3.0839$, d.f. $=4, P<0.05)$ and in Weeks $7-10(t=2.9832$, d.f. $=4, P<0.05)$. Indeed, 11 of the 15 lowest values occurred in nocturnal samples, although twice as many collections had been made during the light phase.

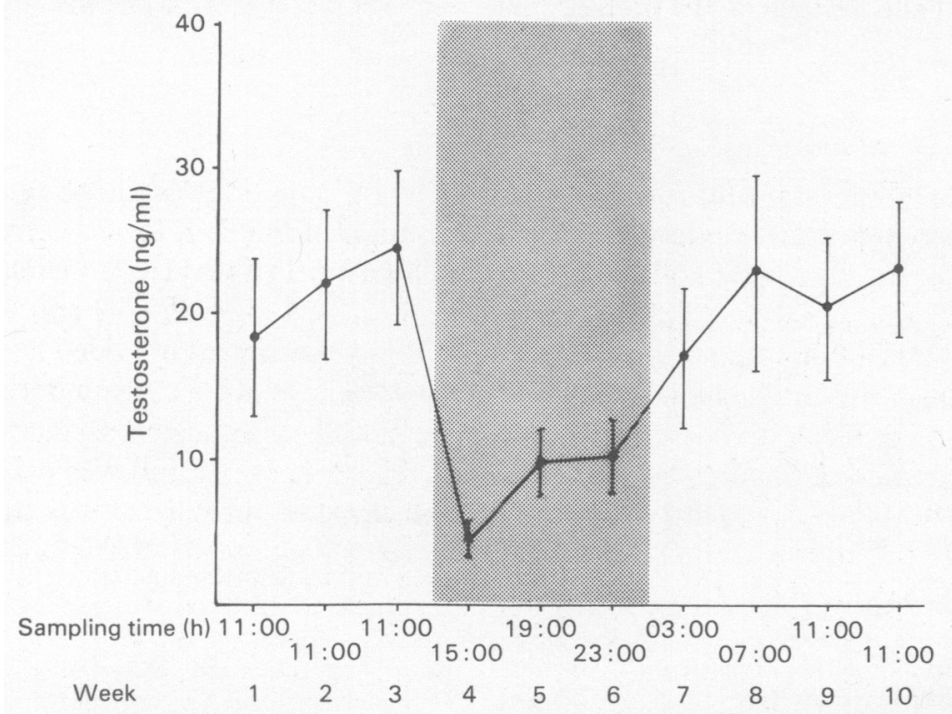

Text-fig. 1. Concentrations of plasma testosterone (mean \pm s.e.m.) in adult male monkeys sampled once weekly at different times of day during 10 consecutive weeks. Stippled area $=$ period of darkness. $\mathrm{N}=6$ for Weeks $1-3$ and 5 for Weeks $4-10$.

\section{Discussion}

Male owl monkeys show marked daily fluctuations in circulating testosterone and concentrations are highest in the light, when the animals are inactive or asleep. Sleep in owl monkeys consists of 5 stages similar to those recorded for baboons or man (Perachio, 1971). In the owl monkey testosterone levels are lowest during the hours of darkness when the animals are most active. This daily testosterone rhythm is the reverse of that found in the ring-tailed lemur, rhesus monkey and bonnet monkey, which are diurnal and have a nocturnal elevation of testosterone. However, the lower levels of testosterone during the periods of activity and the highest level during rest or sleep in all four of these species suggests that, for some non-human primates, daily fluctuations in circulating testosterone may correlate with activity cycles and only secondarily with changes in illumination.

The only other New World primate which has been studied to determine daily fluctuations in androgens is the Peruvian squirrel monkey (Saimiri sciureus). Wilson, Brown \& Wilson (1978) reported very high androgen (testosterone + dihydrotestosterone) levels in male squirrel monkeys but no diurnal variation was observed. Interpretation of data obtained in the above study is complicated by the finding that repeated sampling caused androgen levels in male squirrel monkeys to fall from a mean of 61.9 to $15.0 \mathrm{ng} / \mathrm{ml}$. Stress may lead to reductions in circulating testosterone, as found in male rhesus monkeys (Rose, Gordon \& Bernstein, 1972; Phoenix, Dixson \& Resko, 1977) and in male hamadryas baboons (Goncharov et al., 1979). In the present experiment samples were taken at weekly intervals and there were no long-term effects of this procedure upon levels of plasma testosterone.

This investigation was supported by grants from the Wellcome Trust (U.K.) and from the malaria component of the UNDP/World Bank/WHO Special Programme for Research and 
Training in Tropical Diseases. We also thank Dr C. Edwards and Professor J. Landon (St Bartholomew's Hospital) for the use of radioimmunoassay facilities; Dr A. S. McNeilly and D. W. Davidson (M.R.C. Unit of Reproductive Biology, Edinburgh) for DHT determinations; D. Fleming and Dr R. D. Martin for assistance in collecting blood samples, Mrs J. Hunter for advice on statistical methods and Mrs B. Murrill for expert care of the animals.

\section{References}

Dixson, A.F., Gardner, J.S. \& Bonney, R.C. (1980) Puberty in the male owl monkey, a study of physical and hormonal development. Int. J. Primatol. 1, 129-139.

Goncharov, N.P., Taranov, A.G., Antonichev, A.V., Gorlushkin, V.M., Aso, T., Cekan, C.Z. \& Diczfalusy, E. (1979) Effect of stress on the profile of plasma steroids in baboons (Papio hamadryas). Acta endocr., Copenh. 90, 372-384.

Goodman, R.L., Hotchkiss, J., Karsch, F.J. \& Knobil, E. (1974) Diurnal variations in serum testosterone concentrations in the adult male rhesus monkey. Biol. Reprod. 11, 624-630.

Kavanau, J.L. \& Peters, C.R. (1976) Activity of nocturnal primates: influences of twilight zeitgebers and weather. Science, N.Y. 191, 83-86.

Lincoln, G.A., Rowe, P.H. \& Racey, R.A. (1974) The circadian rhythm in plasma testosterone concentration in man. In Chronobiological Aspects of Endocrinology, pp. 137-149. Eds J. Aschoff, F. Cerena \& F. Halberg. Symposia Medica Hoechst 9 , Schattauer Verlag, Stuttgart.

Michael, R.P., Setchell, K.D.R. \& Plant, T.M. (1974) Diurnal changes in plasma testosterone and studies on plasma corticosteroids in non-anaesthetized male rhesus monkeys (Macaca mulatta). J. Endocr. 63, 325-335.

Moynihan, M. (1964) Some behavior patterns of platyrrhine monkeys. I. The night monkey (Aotus trivirgatus). Smithsonian Miscell. Coll. 146, 1-84.

Mukku, V., Prahalda, S. \& Moudgal, N.R. (1976) Effect of constant light on nychthermeral variations in serum testosterone in male Macaca radiata. Nature, Lond. 260, 778-780.

Perachio, A.A. (1971) Sleep in the nocturnal primate Aotus trivirgatus. In Proc. 3rd Int. Congr. Primatol. Vol. 2, pp. 54-64. Eds J. Biegert \& W. Leutenegger. Karger, Basel.

Phoenix, C.H., Dixson, A.F. \& Resko, J.A. (1977) Effects of ejaculation on levels of testosterone, cortisol and luteinizing hormone in peripheral plasma of rhesus monkeys. J. comp. Physiol. Psychol. 91, 120-127.

Rose, R.M., Gordon, T.P. \& Bernstein, I.S. (1972) Plasma testosterone levels in the male rhesus: effects of sexual and social stimuli. Science, N.Y. 178, $643-645$.

Van Horn, R.N., Beamer, N.B. \& Dixson, A.F. (1976) Diurnal variations of plasma testosterone in two prosimian primates (Galago crassicaudatus crassicaudatus and Lemur catta). Biol. Reprod. 15, $523-528$.

Wilson, M.I., Brown, G.M. \& Wilson, D. (1978) Annual and diurnal changes in plasma androgen and cortisol in adult male squirrel monkeys ( $S$. sciureus) studied longitudinally. Acta endocr., Copenh. 87, 424-433. 